COMUNICAÇÃO

\title{
FEMININO X MASCULINO NAS PERSONAGENS FEMININAS DE SHAKESPEARE
}

\author{
ANA MARIA KESSLER ROCHA
} O objetivo deste trabalho é analisar quatro personagens femininas na obra
de William Shakespeare as quais assumem identidades ou atitudes masculinas: Portia, em The merchant of Venice, Rosalind, em As you like it, Viola, em Twelfth night, e Lady Macbeth, em Macbeth. Esta análise se propõe a apontar dois fatores: primeiro, que a forma como esses disfarces elaborados por volvimento varia das comédias para a tragédia, podendo-se notar um desenvolvimento crescente nos mesmos; segundo, que no final de sua "experiência perder sua identidade, ou deve retornar ao seu papel feminino, sob pena de ter a ordem social e cósmica.

Para estabelecer a natureza dos disfarces masculinos assumidos nas comédias e na tragédia, é necessário lembrar as diferenças existentes entre elas do ponto de vista da dicotomia feminino $\mathrm{x}$ masculino. Basicamente, pode-se dizer que a comédia é feminina e a tragédia, masculina, mas devemos antes examinar os passos pelos quais chegamos a essa conclusão.

A tragédia enfoca uma personagem central, sempre masculina, num mundo que é governado por normas e conceitos essencialmente masculinos (força, poder, guerra, etc.) e onde toda a ação se desenrola do ponto de vista do herói. A comédia, por outro lado, na busca da harmonia, aborda todo um grupo social onde as personagens femininas são tão ou mais importantes do que as masculinas. A tragédia é linear em sua estrutura e sempre termina em morte, destruição, desintegração - de forma irrevogável. A comédia é circular, acenando no final, , através de um casamento ou outra cerimônia festiva, com a promessa de um recomeço, de continuação, integração e permanência.

A presença da natureza, por exemplo (bosques, flores, riachos, animais, ete.), muito mais sentida e mais importante na comédia do que na tragédia, o 6 feminina enquanto força criadora, e protetora - atributos essencialmente femininos. Na tragédia, onde as forças naturais são apresentadas como destruUivas, nĨo o ș̃o por si só, mas como conseqüência de atos humanos (leia-se masculinos), que propiciam a quebra da ordem natural do universo (ruptura no Macrocosmo que traz o caos às demais esferas).

Iละas consideraçб̄es são necessárias para que possamos analisar os disfarces 00 identidades masculinas nas peças em questão. Observamos, inicialmente que nas trể comédias esse assumir uma identidade masculina vem acompanhade de indumentíria e comportamento masculinos. Portia transforma-se em balthasar usando roupas de um doutor em leis e falando como tal; Rosalind

Aă Maria Ke siler Hecha é professora na Universidade Federal do Rio Grande do Sul 
passa a ser Ganymede vestindo-se e comportando-se como um pastor de ovelhas, e Viola assume a identidade de um simples pagem travestindo-se como Cesario.

Devemos levar em consideração, igualmente, as convenções teatrais da Renascença que permitiam a qualquer ator assumir um disfarce completamente diverso de sua personagem original, sem ser reconhecido, bastando para isso trocar de roupa. Nos casos aqui estudados, o disfarce é ainda mais perfeito uma vez que, segundo outra convenção da época, os papéis femininos eram representados por meninos. Temos assim uma situação curiosa em que um rapaz usava um vestido e uma peruca para interpretar um papel feminino, e então, por exigência desse mesmo papel, assumia novamente uma identidade masculina. Ficava pois muito mais fácil para esse ator-menino transmitir à audiência um disfarce convincente.

Na tragédia, a situação é diferente. Quando ocorrem, os disfarces são dos homens, uma vez que, como vimos, trata-se de um mundo predominantemente masculino. É o caso de Hamlet, por exemplo, ou Edgar, em King Lear, ambos assumindo um disfarce de "pretensa" loucura. No que diz respeito às personagens femininas, como Lady Macbeth, temos outra realidade. Ela não usa roupas masculinas, nem assume uma identidade masculina - de princípio a fim na peça ela é LADY Macbeth, sem disfarces. No entanto, das quatro personagens analisadas aqui, ela é a que mais se aproxima do pólo masculino na dicotomia feminino $\mathrm{x}$ masculino.

Em Macbeth, temos ainda a caracterizacão das três feiticeiras, descritas no início da peça como "mulheres de barba". Sua aparência, bem como seu famoso estribilho - "fair is foul and foul is fair" - atestam o duplo sentido atribuído a características femininas e masculinas nessa peça. Voltaremos a esse assunto mais tarde.

Outro aspecto a ser considerado na distinção entre as comédias e a tragédia é a finalidade do disfarce. O objetivo de Portia ao assumir o disfarce de Balthasar em TMV é ser aceita no tribunal de Veneza (um local só permitido aos homens) para poder salvar Antonio. Rosalind busca proteção em seu disfarce como Ganymede, uma vez que foi banida por seu tio e deve viver na floresta, longe da segurança da corte. O mesmo acontece em Twelfth night onde Viola, uma estrangeira náufraga em Illyria, tenta proteger-se na pele de Cesário.

Em suma, nessas peças, a finalidade do disfarce está intimamente associada àquela característica feminina que identificamos na comédia - dar e buscar proteção, criar e manter a harmonia e a paz, tanto no lar quanto na comunidade.

Por outro lado, na tragédia, o que leva Lady Macbeth a assumir atitudes tão masculinas? Ambição? Determinação? Inclinação de caráter? O dever de uma boa esposa? Essas e outras possibilidades já foram amplamente debatidas pelos críticos; qualquer delas, ou todas, podem ser comprovadas, mas não é este o ponto em discussão aqui. O que devemos lembrar é que na tragédia como já vimos, o propósito é desintegrar, destruir, desarticular, e isso Lady Macbeth consegue fazer exemplarmente. Mesmo se considerarmos que ela apenas encoraja e apóia seu marido, não devemos esquecer que o que ela in. centiva é a decisão de trair, matar, tomar o pode pela força - atitudes e princípios de um mundo governado por valores masculinos.

Para que notemos o desenvolvimento na elaboração desses disfarces de uma peça para outra, é necessário que as estudemos separadamente.

Em The merchant of Venice (TMV), vemos Portia assumir a identidade de Balthasar, um jovem "doutor em leis", supostamente enviado pelo advogado Belario, de Pádua, para ajudar Antonio na corte de Veneza. O disfarce de Portia se origina de seu amor por Bassanio; ela ama Bassanio, o qual ama Antonio e deve a este, literalmente, seu casamento com ela. Uma vez que o dinheiro é um aspecto central nessa comédia, até mesmo as relações pessoais se realizam através de acordos e negociações. Antonio deve a Shylock por causa de Bassanio, e Bassanio deve a Antonio por causa de Portia. E se a vida do mercador está em risco por causa dessa mesma dívida, então Portia também deve a Antonio, e faz uso de seu disfarce para ajudá-lo.

Ela adentra o tribunal em igualdade de condições com os homens, exercendo um grau de independência que não the seria permitido em sua identidade feminina e fora de seu mundo feminino em Belmont. Durante o julgamento, Portia se utiliza da linguagem dos homens, das leis feitas pelos homens e dos valores da sociedade masculina para salvar Antonio da dívida fatal cobrada por Shylock. É curioso e até mesmo irônico que nenhum dos homens em Veneza tivesse conhecimento para tomar tal atitude; é preciso que uma mulher, disfarçada como um deles faça uso da mesma lei invocada por Shylock e submissamente aceita pelos outros, para anular e inverter o curso do processo.

No entanto, apesar de seu objetivo ser totalmente feminino - salvar, proteger e amar - o que Portia faz, na verdade, é perpetuar os valores masculinos da sociedade veneziana. Ao reverter o processo contra Shylock, ela reforça o preconceito religioso, a hostilidade contra estrangeiros e os valores morais vigentes; em outras palavras, Portia ajuda a manter o "establishment" em Veneza.

Outro aspecto interessante que convém lembrar é a duração desse disfarce. Vemos Portia em sua identidade masculina apenas no ato IV que, conquanto seja longo, tem apenas duas cenas. No ato $\mathrm{V}$, a ação retorna Belmont, aquele mundo essencialmente feminino que se opõe à rigidez, à sobriedade e à formalidade do mundo masculino de Veneza. Nele, Portia reassume sua identidade feminina; sua "aventura masculina" está terminada, seu objetivo foi alcançado. Ao contar sua estória e esclarecer o equívoco do anel, ela dá uma lição em Bassanio e Antonio sobre a importância do amor e dos valores femininos que o acompanham. $\hat{E}$ ela que restabelece a ordem e a harmonia, esclarecendo os mal-entendidos e transmitindo as boas novas a Antonio.

Mas não devemos ficar com a impressão de que Portia se coloca em posiçı̃o de superioridade no final. Embora tenha provado sua capacidade intelectual e seu valor como indivíduo, ela retorna à atitude submissa do ato III, cena 2, ao aceitar o pedido de perdão de Bassanio endossado por Antonio. O anel que passa das mãos de Portia para Antonio e então para Bassanio aimboliza claramente esse retorno. Não poderia ser de outro jeito; a ordem 
harmônica do mundo das comédias precisa ser respeitada - cada coisa em seu lúgar, cada qual com seu papel.

Resumindo, em TMV temos um disfarce masculino que é temporário, que tem um objetivo específico bem claro, e que é abandono depois em favor da identidade feminina, que prevalece.

A situação já é um pouco diferente em As you like it (AYLI). O objetido de Rosalind ao fazer uso de um disfarce masculino é, como vimos, proteger-se dos perigos que o banimento da corte possa the trazer. Juntamente com sua prima Célia e o bobo, Touchstone, ela abandona a "segurança" do mundo civilizado (masculino) pelo desconhecido na floresta de Arden, que simboliza - "mundo verde" em Shakespeare, o mundo natural e, portanto, feminino.

Ao mesmo tempo em que lhe garante segurança, o disfarce como Ganymede permite também que Rosalind alcance um grau de independência e liberdade que não the era permitido na corte. No seu papel masculino, ela automaticamente assume a liderança do trio; é ela que toma as decisões, é ela que conversa e se relaciona com o mundo exterior em Arden, principalmente com os homens. Em contrapartida, sendo aceita como um homem, ela é tratada e respeitada como tal pelos outros - eles a escutam, aceitam seus conselhos, e seguem suas instruções. Nisso podemos compará-la a Portia, cujas decisões sobre os destinos de Shylock e Antonio são acatadas pelo tribunal

É interessante notar que, assumindo um papel masculino, Rosalind não apenas toma a si a liderança do grupo, como também a responsabilidade de proteger e cuidar de seus companheiros. No início da cena 4 do segundo ato por exemplo, ela encoraja e conforta Aliena após a longa caminhada até Arden. Assume, portanto, uma característica masculina - o cavalheiro que protege a dama.

Além disso, a nova identidade permite que Rosalind tenha controle sobre todos que se relacionam com ela, uma vez que só Célia e Touchstone conhecem seu segredo. Isso the confere a vantagem da onisciência na peça; Rosalind lida com fatos de que só ela e o espectador têm conhecimento, manipulando e confundindo as demais personagens - o que causa, a princípio, grande divertimento. As cenas em que Ganymede se propõe a ajudar Orlando a "curar-se" de seu amor por Rosalind é o melhor e mais conhecido exemplo (III, 2 e IV, 1 ).

Devemos notar, porém, que mesmo sendo mulher em seu disfarce ela é portadora de valores e idéias masculinas. Assim como Portia, Rosalind ajuda a manter o status quo e reproduz o pensamento masculino em relação à posição da mulher na sociedade.

Aos poucos, no entanto, o fardo da onisciência e da responsabilidade vai se tornando pesado para Rosalind, principalmente se observarmos que, a todo instante, ela nos lembra de sua verdadeira identidade, sua feminilidade e fragilidade (II,4 e III,2). O casamento de Oliver e Aliena, marcado para "amanhâa", determina o fim da "diversão" e precipita o final da ação.

No ato V, cena 2, Ganymede promete trazer a situação a bom termo para todos e, logo depois, na cena 4 , Rosalind e Celia reaparecem em suas roupas da corte, voltando a assumir suas identidades originais.

Como Portia, Rosalind prova sua esperteza e seu valor como indivíduo também como no caso de Portia, a entrega de Rosalind $d$ completa e dupla: primeiro ao pai, depois a Orlando. Ela reassume integralmente seu papel feminino, como filha e como esposa ("To you I give myself - I am yours")

Ao contrário de Portia, no entanto, Rosalind não oferece qualquer explicação para seu disfarce masculino, sendo suas duas últimas falas na peça a simples ratificação de sua entrega. Outra diferença em relação à peça anterior é a duração do disfarce. Rosalind e Celia assumem suas identidades falsas no ato II, cena 4 e as mantêm até o final, em V,4, são quase quatro atos inteiros, enquanto que em TMV o disfarce toma apenas um ato.

Como podemos notar, há algumas diferenças importantes de uma peça para a outra - o motivo, a duração e, é claro, a própria natureza do disfarce. Em Twelfth night (TN), essas diferenças são ainda mais marcantes.

Viola também procura proteger-se, como Rosalind ao assumir o papel de Cesario. Náufraga e estrangeira numa terra desconhecida, separada de seu irmão gêmeo Sebastian, que ela julga ter morrido, a jovem passa por um período de intensa insegurança no que se refere não apenas à sua integridade física, mas também emocional e psicológica.

Sua primeira intenção é servir Olivia para, como ela, esconder-se do mundo. Ao saber que a condessa não recebe ninguém, Viola decide oferecer seus serviços ao duque, disfarçada como Cesario. A partir daí, sem qualquer outra explicação para seu disfarce, ela apenas espera, dando tempo ao tempo $(\mathrm{I}, 2)$.

No nível emocional, vemos uma jovem insegura e inexperiente jogada num ambiente estranho, e que não sabe o que esperar dessa nova vida. Ela perde seu senso de identidade porque perdeu o rumo, o lar, e o irmão, tudo ao mesmo tempo. Viola está emocionalmente, além de fisicamente perdida.

No nível psicológico, esta peça apresenta uma dificuldade adicional Viola e Sebastian são gêmeos quase idênticos e, no decorrer da ação, um é tomado pelo outro em diversas situações. Sabemos que há toda uma tradição folclórica e literária envolvendo estórias de gêmeos cujas identidades e perso. nalidades se sobrepõem e complementam. No caso de Viola, podemos adivinhar em seu disfarce como Cesário um desejo inconsciente de substituir o irmão considerado morto; ou seja, uma tentativa de "ser" Sebastian. Assim como Olivia escolhe o sacrifício de manter luto por seu irmão durante sete anos, Viola sacrifica seu "eu feminino", assumindo uma identidade masculina.

Além disso, cortejar Olivia em nome do duque, estando apaixonada por ele, apenas aumenta ainda mais o problema de identidade de Viola. Ela oscila entre o masculino e o feminino, dividida por um forte conflito emocional.

Como vemos, a elaboração do disfarce em TN é bem mais complexa do que nas outras duas peças. Em se tratando de uma comédia, porém, a complexidade deve ser esclarecida no final; a ambigüidade deve ser resolvida e os disfarces abandonados. $\hat{E}$ o que acontece com Viola; ela retoma sua identidade feminina, mas, reforçando o aspecto psicológico de elo entre gêmeos, só o faz quando se vê face a face com seu irmão, Sebastian. Mesmo assim, esse retorno da "aventura masculina" é apenas parcial no fim da peça, pois ela não chega a retomar suas roupas femininas, como Portia e Rosalind. O próprio duque Orsino continua a chamála de "Cesario", "que enquanto fores homem, gerís Cesario", (Grifo meu; V, 1) 
Também em termos de duração o disfarce de Viola difere dos outros, pois é bem mais longo, tomando praticamente toda a peça $(I, 4$ até $\mathrm{V}, 1)$.

Finalmente, passamos à análise da tragédia. Como vimos, o mundo trágico é totalmente diverso daquele das comédias; é, de princípio a fim, um mundo masculino, onde imperam valores e regras masculinas. Em Macbeth, mais do que nas outras tragédias, isso é verdade - guerra e traição abrem a peça e continuam, acrescidas de crime, medo, caos e destruição geral.

Nesse ambiente, Lady Macbeth tem uma função primordial. Se ela seguisse o padrão adequado ao seu papel de acordo com a polaridade feminino $\mathrm{x}$ masculino em Shakespeare, seria apenas mais uma personagem feminina secundária em relação ao herói. No entanto, ao fazê-la transgressora da ordem natural, ou seja, feminina, Shakespeare a eleva a um plano de igualdade com Macbeth - pelo menos no início da peça. Se é verdade que em tempo de guerra a mulher deve se equiparar ao homem, ser forte e esconder sua fraqueza, sua feminilidade, Lady Macbeth leva essa máxima ao extremo.

Para apoiar seu marido, para dar-lhe coragem de assassinar Duncan, ela abandona voluntariamente seu papel feminino (monólogo em I,5), identificando-se de imediato com os valores do gênero oposto. Ela não usa disfarces ou linguagem masculina; mesmo as imagens que usa se originam no mundo feminino (bebês, leite materno, seio materno, etc.), mas são imagens de escárnio e destruição dos valores que representam.

Essa troca de valores é simbolizada pela caracterização das três feiticeiras, que são mulheres e, no entanto, têm barba. O verso que cantam - "fair is foul and foul is fair" - expressa claramente o tema central da peça: a ambigüidade, o duplo sentido das coisas, aparência $\mathrm{x}$ realidade (tema recorrente em Shakespeare)

Assim, Lady Macbeth é, a um tempo, "fair" (= bela, como mulher) e "foul" (= má, ou feia, como homem). Ao assumir plenamente o lado masculino em detrimento de sua personalidade feminina, ela determina sua própria destruição, pois essa renúncia, esse rompimento com a natureza, tem um alto preço a ser pago.

Como dissemos anteriormente, a personagem feminina que assume disfarces ou atitudes masculinas sem retornar ao seu papel original, corre o risco de perder sua própria identidade, sua sanidade, ou sua vida. Na tragédia, esse retorno é impossível, uma vez que toda a ação trágica é irrevogável, e Lady Macbeth deve sofrer sua punição - sonambulismo, alucinação, e suicídio.

Concluímos, dessa forma, que a elaboração dos disfarces aqui analisados não varia apenas da comédia para a tragédia; a diferença se apresenta também de uma peça para outra. Podemos acompanhar um movimento crescente em duração e complexidade, culminando na criação de uma personagem como Lady Macbeth que, mesmo sem disfarces, aproxima-se do pólo masculino mais do que Portia, Rosalind ou Viola.

Vimos também que nas comédias, uma vez cumpridos seus objetivos, os disfarces são abandonados, pois é necessário que a ordem e a harmonia sejam mantidas na sociedade. Na tragédia, isso não acontece devido à irrrevogabilidade da ação; o que foi feito não pode ser desfeito, e a quebra da ordem natural traz, inevitavelmente, morte e destruição.

\section{REFERÊNCIAS BIBLIOGRĀFICAS}

SHAKESPEARE, W As you like it. The New Penguin Shakespeare. London, Penguin, 1967.

- Macbeth The Folger Library Shakespeare. New York, Washingthon Square Press, 1959.

- The merchant of Venice. The New Penguin Shakespeare. London, Penguin, 1967 -. Twelfth night. New Swan Shakespeare. London, Langmans, 1965. 